\title{
Consultation time, workload, and problems for audit in outpatient clinics
}

\author{
James W Partridge
}

\begin{abstract}
Fifty four of 74 paediatricians in the West Midlands (43 general medical, 11 subspecialist) replied to a postal questionnaire about their outpatient practice: 37 timed each consultation in one clinic. On average, subspecialty consultations lasted 37 minutes for new patients and 29 minutes for review. In general clinics new patient consultations took 23 minutes, review 12. Mean 'single handed' general clinic size was 18 , clinics with assistants 24 ; subspecialist clinics nine and 15. Four to five new patients and nine to 19 review patients were booked per clinic on average; $17 / 51$ clinics used block booking, 34 provided individual appointment times. Mean referral delay was 4.9 weeks, mean clinic wait 22 minutes, and non-attendance averages $16-29 \%$.

Solutions are suggested to four main problems: non-attendance, referral delay, unpunctuality and disorganisation, with audit levels for paediatric outpatient activity.
\end{abstract}

All paediatricians spend part of their working lives in outpatient clinics. This work is often isolated, unobserved by our peers, and usually not subject to research. ${ }^{1-3}$ It is not easy to discover whether an individual workload is excessive and whether other paediatricians have found better solutions to a potentially increasing burden. In particular, time allocated to individual patients seems less and less sufficient, but if more time is provided, then either more clinics must be held, or fewer patients seen.

\section{Methods}

I sent all 74 consultant paediatricians who worked in the West Midlands in 1989-90 a questionnaire about their next typical outpatient clinic for newly referred ('new') and follow up ('review') National Health Service patients. They were asked to provide the appointment list, details of their appointment
South Warwickshire Hospital, Lakin Road, Warwick CV34 5BW

Correspondence to: Dr Partridge.

Accepted 30 October 199 No reprints will be available. system, and to indicate whether they worked alone or with assisting doctors. I asked them to record the time at the beginning and the end of each consultation.

\section{Results}

Fifty nine paediatricians replied, and 54 gave data of varying completeness. Eleven provided details of a subspecialty clinic such as developmental paediatrics or cardiology and 43 described general medical paediatric clinics. Eighteen worked single handed in the clinics and 36 had assisting doctors. Forty nine clinics combined new and review patients, two clinics were for review patients only, and three paediatricians saw new and review patients in separate clinics.

\section{COMPOSITION OF CLINICS}

Table 1 shows the numbers of new and review patients in 54 clinics. Subspecialty clinics tended to be smaller (mean $=12$ patients) than general clinics (21 patients), with a larger percentage of new patients (32\% compared with $23 \%$ ). General clinics with assisting doctors were larger than single handed clinics (24:18) and contained a smaller percentage of new patients $(20 \%: 27 \%)$.

\section{APPOINTMENT SYSTEM}

Seventeen paediatricians used 'block booking'-that is, groups of patients with simultaneous appointments, and 34 provided separate appointments for individual patients at the intervals shown in table 2 . Eleven paediatricians allocated the same time to new and review patients, while 23 allowed more time for new patients. The systems most frequently used (17 clinics) provided either five or 10 minutes for review patients and 10 or 15 minutes for new patients.

No system provided any flexibility in allocating different amounts of time for different patients, though additional appointments were often inserted between bookings. Twins and siblings were sometimes given a single appointment.

\section{DURATION OF CONSULTATION}

Consultation times could be calculated for 37 clinics (table 3). Consultations usually exceeded the time provided: in only six clinics was the timing appropriate. Variations in times within and between clinics was considerable. Consultations lasted longer with new patients, at subspecialty clinics, and with assisting doctors. 
Table 2 Appointment system used in 51 clinics

\begin{tabular}{ll}
\hline & $\begin{array}{c}\text { No of } \\
\text { clinics }\end{array}$ \\
\hline $\begin{array}{l}\text { Block booking } \\
\text { Individual timing } \\
\text { (min appointments) }\end{array}$ & 17 \\
New patients & 34 \\
10 & 10 \\
15 & 13 \\
20 & 5 \\
$30+$ & 6 \\
Review patients & 13 \\
5 & 11 \\
10 & 5 \\
20 & 5 \\
$30+$ & \\
\hline
\end{tabular}

WAITING TIME

In 33 clinics it was possible to calculate the interval between the booked time and the start of the consultation. These intervals are expressed as means per clinic in table 4, with an analysis of the number of patients having to wait more than 30 and 60 minutes. Longer waiting times were more frequent in clinics with 24 or more patients and when block booking systems were used. In two subspecialty clinics all the patients were seen on time.

\section{REFERRAL INTERVAL}

For new patients only, the interval between their attendance and the date of the referring letter was calculated. Table 5 shows the mean referral intervals for 35 clinics and whether some patients were seen within three weeks, or over seven weeks, from referral.

Table 3 Duration of consultations in 37 clinics (min)

\begin{tabular}{llll}
\hline & $\begin{array}{l}\text { Overall } \\
\text { mean }\end{array}$ & $\begin{array}{l}\text { Range of } \\
\text { means }\end{array}$ & $\begin{array}{l}\text { 10th-90th } \\
\text { centiles }\end{array}$ \\
\hline New patients & 37 & $25-45$ & $20-40$ \\
$\quad$ Subspecialists & 23 & $11-40$ & $15-32$ \\
$\quad$ General paediatricians & 23 & $18-45$ & $20-45$ \\
Review patients & 29 & $5-20$ & $6-17$ \\
$\quad$ Subspecialists & 12 & & \\
\hline
\end{tabular}

Table 4 Waiting time in 33 clinics

$\left.\begin{array}{lr}\hline \text { Mean waiting time (min) } & 0-64 \\ \text { Range } & 6-40 \\ \text { 10th-90th centiles } & 22 \\ \text { Overall mean } & 0-195 \\ \text { Longest actual wait (min) } & \\ \text { No of patients with } 30+\text { min wait (No of clinics) } & 8 \\ 0 & 6 \\ 1-2 & 14 \\ 3-5 & 5\end{array}\right\} 33$

Table 5 Interval between referral letter and attendance in 35 clinics

\begin{tabular}{|c|c|c|}
\hline $\begin{array}{l}\text { Mean interval (weeks) } \\
\text { Median } \\
\text { Range } \\
\text { l0th-90th centile }\end{array}$ & $\begin{array}{l}4 \cdot 9 \\
4 \\
1-15 \\
2-8\end{array}$ & \\
\hline No of patients with intervals $7+$ weeks (No of clinics) & & \\
\hline $\begin{array}{l}0 \\
1-2 \\
4+\end{array}$ & $\begin{array}{r}19 \\
9 \\
7\end{array}$ & 35 \\
\hline No of patients with intervals $\leqslant 3$ weeks (No of clinics) & & \\
\hline $\begin{array}{l}0 \\
1-\geqslant 2\end{array}$ & $\begin{array}{l}11 \\
24\end{array}$ & 35 \\
\hline
\end{tabular}

NON-ATTENDANCE

Overall, 187 children did not attend out of 921 booked appointments at 47 clinics $(20 \%$ nonattendance): this excludes cancelled appointments (table 6). Attendance was better at suspecialty clinics and by new patients; a long referral interval may contribute to nonattendance. There was little difference in attendance at general clinics with or without assisting doctors.

\section{DISCONTINUITY}

The paediatricians were asked to select the patient reviewed over the longest period, and to list the doctors this patient had seen on the previous 10 visits; 35 replied. In nine clinics this patient had seen the same consultant on each of the last 10 visits, in 22 clinics the same consultant had been seen on at least half of the visits, and in four the same consultant had been seen on less than half. The most extreme example of discontinuity was the patient who had seen six different doctors at the past 10 appointments.

\section{DURATION OF CLINICS}

Clinics were usually scheduled from $9 \mathrm{am}-12.30$ pm or $2 \mathrm{pm}-5.30 \mathrm{pm}$. The data from 37 paediatricians indicated how much of these 3.5 hours was spent on consultation: the median was 3 hours 12 minutes, with a range from 5 hours to 1 hour 45 minutes.

Twenty one clinics started within 15 minutes of the first appointment, 10 within 15-30 minutes, and six were 30 or more minutes late. Consultants sometimes attributed their lateness to inescapable commitments or inclement weather (the survey was in November). Consultations often continued well beyond the allocated $3 \cdot 5$ hours. Morning clinics were more likely to over-run than afternoon ones (14 of 23 morning clinics, three of 14 afternoon clinics).

Paediatricians recorded the consultation time only, not that spent on other activities such as preparation, teaching, supervision, or dictating letters (although one subspecialist spent 25 minutes answering telephone inquiries from his consultant colleagues).

\section{Discussion}

There are limitations to this sample of paediatric outpatient clinics, although $73 \%$ of paeditricians in the West Midlands participated. Some replied that to complete a questionnaire, and to time each consultation during a busy clinic, were the 'final straws'. Only one clinic from each

Table 6 Non-attendance in 47 clinics for new and review patients

\begin{tabular}{|c|c|c|c|c|c|c|c|c|}
\hline & \multicolumn{2}{|c|}{ All clinics } & \multicolumn{2}{|c|}{11 Subspecialty } & \multicolumn{2}{|c|}{16 General clinics (alone) } & \multicolumn{2}{|c|}{20 General clinics (assisted) } \\
\hline & New & Review & New & Review & New & Review & New & Review \\
\hline $\begin{array}{l}\text { Non-attenders } \\
\text { Total booked } \\
\% \text { Who did not attend } \\
\% \text { Both new and review }\end{array}$ & $\begin{array}{r}26 \\
205 \\
13\end{array}$ & $\begin{array}{r}161 \\
716 \\
22\end{array}$ & $\begin{array}{r}1 \\
33 \\
3\end{array}$ & $\begin{array}{r}23 \\
117 \\
20\end{array}$ & $\begin{array}{r}7 \\
74 \\
9\end{array}$ & $\begin{array}{r}56 \\
201 \\
28\end{array}$ & $\begin{array}{l}18 \\
98 \\
18\end{array}$ & $\begin{array}{r}82 \\
398 \\
21\end{array}$ \\
\hline
\end{tabular}

For new patients in 30/47 clinics, all attended; in 5/47 clinics, $2+$ did not attend. For review patients the lowest $\%$ who did not attend was $6 \%(1 / 17$ booked) and the highest was $70 \%$ (7/10 booked); $10-90$ th centiles $8-40 \%$. 
Table 7 Comparative date: non-attendance, clinic size, and composition

\begin{tabular}{|c|c|c|c|c|c|c|c|c|}
\hline & \multicolumn{2}{|c|}{$\begin{array}{l}\text { Non-attendance } \\
\text { rates }(\%)\end{array}$} & \multicolumn{3}{|c|}{$\begin{array}{l}\text { Mean No of } \\
\text { patients/clinic }\end{array}$} & \multicolumn{3}{|c|}{$\%$ Of new/total patients seen } \\
\hline & $\begin{array}{l}\text { New } \\
\text { patients }\end{array}$ & $\begin{array}{l}\text { Review } \\
\text { patients }\end{array}$ & Median & $\begin{array}{l}\text { 10th } \\
\text { centile }\end{array}$ & $\begin{array}{l}\text { 90th } \\
\text { centile }\end{array}$ & Median & $\begin{array}{l}\text { 10th } \\
\text { centile }\end{array}$ & $\begin{array}{l}\text { 90th } \\
\text { centile }\end{array}$ \\
\hline $\begin{array}{l}\text { All paediatric clinics in England }(1988)^{*} \\
\text { All paediatric clinics in the West Midlands }(1988)^{*} \\
\text { Inner city general hospital 1985-6† } \\
\text { Current survey }\end{array}$ & $\begin{array}{l}13 \\
13 \\
25 \\
13\end{array}$ & $\begin{array}{l}17 \\
20 \\
35 \\
22\end{array}$ & $\begin{array}{l}12 \\
12 \\
\text { NA } \\
14\end{array}$ & $\begin{array}{l}\text { NA } \\
8 \\
\text { NA } \\
9\end{array}$ & $\begin{array}{l}\text { NA } \\
17 \\
\text { NA } \\
28\end{array}$ & $\begin{array}{l}18 \\
18 \\
23 \\
26\end{array}$ & $\begin{array}{l}\text { NA } \\
12 \\
\text { NA } \\
13\end{array}$ & $\begin{array}{l}\text { NA } \\
26 \\
\text { NA } \\
38\end{array}$ \\
\hline
\end{tabular}

*Data supplied by West Midland Regional Health Authority 1989.

†Andrews et al. ${ }^{2} \mathrm{NA}=$ not available.

participant was studied, and $45 \%$ of them said the selected clinic was not typical-referring to computer errors, over booking, absent staff, and difficult weather conditions. Though these were sometimes quoted as examples of atypicality, sometimes these were seen as being entirely representative. The concept of a 'typical' clinic may be elusive, discontinuity being a characteristic of hospital activity.

My intention was to discover the length of time of each consultation and the size and workload of my colleagues' clinics, without changing their normal clinic activity, and without introducing selection. Table 7 shows that two other surveys in this region support my data.

Four main problems in paediatric outpatient clinic practice were identified (though they are not unique to paediatrics).

\section{PROBLEMS}

\section{(I) Non-attendance}

One in five of patients failed to attend. New patients were more likely to attend, particularly those visiting subspecialty clinics. ${ }^{2}$ Non-attendance seemed to be associated with block booking, long clinic waiting times, referral delay, and large clinics (over 24 patients), but the sample was too small for statistical analysis.

Andrews et al concluded that attendance is closely related to the parents' perception of the importance of the problem. ${ }^{2}$ Although others have suggested that unnecessary, automatic reviews ('come again in 3 months') particularly by a succession of junior staff, cause nonattendance, ${ }^{4-6}$ this survey did not find that nonattendance was more frequent in clinics with junior staff assisting. Nor was there evidence that review patients often saw a succession of different doctors.

\section{(2) Referral delay}

New patients waited on average about five weeks from the date of the referring letter before they were seen, with very considerable variation between clinics (1-15 weeks) but very little variation within any particular clinic. Thus, in the clinic with the longest mean delay of 14.6 weeks, the five patients waited 17,16 , 16,16 , and eight weeks; in the clinic with the shortest delay, the intervals were one, one, one, and two weeks.

Some clinics reserved a few vacant booking spaces for urgent new patients, but most followed the policy of allocating the next available appointment to new patients irrespective of urgency. Twenty four of 35 clinics were able to provide at least one new appointment within three weeks of referral.

A mean wait of five weeks for new paediatric referrals is too long. Valman recommends one week for urgent patients and two to three weeks for non-urgent ones, ${ }^{7}$ and with these timings most doctors and patients would concur.

\section{(3) Unpunctuality}

The mean interval between the appointment time and the start of the consultation was 22 minutes. In five clinics a quarter or more of the patients waited 30 minutes or longer. In three other clinics, a quarter of the patients waited an hour or more. The longest wait was 3 hours 15 minutes.

This 'waiting time' was calculated without knowing when patients actually arrived. Some paediatricians mentioned that patients using public transport arrived in surges, making appointment systems inoperative. But paediatricians themselves were also late: six clinics began at least 30 minutes late.

Another reason for unpunctuality was the mismatch between the times allocated for consultations (a popular choice was 15 minutes for new and five minutes for review patients) and the mean times needed for consultations (25 minutes new, 12 minutes review).

Some waiting is probably inevitable, even if paediatricians were punctual. Patients will need weighing, measuring, undressing, and perhaps investigation or sample collections. Waiting may not be a hardship in clinics that have child centred playgrounds. Nevertheless, waiting is a tense time and children get fractious. Paediatricians will need to take more time with tense parents and irritable children, and may feel the need to compensate them for their wait by giving them extra time: the next patients then wait even longer.

\section{(4) Disorganisation}

Ten paediatricians remarked that the clinic was particularly disorganised, and the records from others instanced various muddles.

Computerised appointment systems produce many large sheets of paper that were hard to read. Patients may be listed not in order of attendance but by registration number or alphabetically. 'Double booking' is frequent, and extra patients are squeezed in between appointments. Twins and siblings may be given simultaneous appointments, though in my experience they each need at least the usual allocation of time, if not more. 
Some paediatricians seemed to have little control over the appointment system to judge from their written pleas on the lists, 'Stop this crash booking', 'No more patients at all, thanks'. They were engulfed by a system in which overlarge clinics, constantly interrupted by distractions and telephone calls, were always overrunning. There was no space allocated at the start of the clinic for reviewing the casenotes, at the middle for a tea break, or at the end for the dictation of letters. Some disasters (such as freezing fog) may not be predictable but some problems, such as junior staff absences on leave, can be anticipated. It may be inappropriate for consultants to hold outpatient clinics on days when they are on emergency call without middle grade staff: some arrived late because of emergency calls. Paediatricians accustomed to disorganisation conveyed a sense of weary fatalism in their comments: "Clinic atypical: it started on time', "No notes missing-for once", 'No DNAs [did not attend], usually 4 or 5'. They seemed to be engaged in an activity over which they had little control, yet for which they were ultimately responsible.

\section{SOLUTIONS}

Not all clinics were disorganised and inefficient: some were punctual, with realistic appointment intervals and overall size, and their patients did not wait many weeks to be seen. Such clinics were not necessarily in areas of affluence, nor at well staffed hospitals. One requirement for success is the realisation that the consultant has overall control and therefore the power to make changes.

Large clinics with a low ratio of new to review patients are particularly associated with appointment delays and long waiting times and therefore the need for each review appointment must be critically appraised. Experienced paediatricians learn that ward follow up appointments are often redundant: for example, after pyloromyotomy or lobar pneumonia. It may be rewarding to meet satisfied customers, and instructive to the untrained to learn how quickly these patients recover, but not at the expense of an overloaded clinic. Delegation to general practitioners is usually possible. ${ }^{35}$ Written management protocols may enable the paediatrician to delegate the review of less frequently seen paediatric disorders, with an annual hospital review.

The results of investigations can be conveyed to parents by letter or by telephone. Some paediatricians consider face to face contact is needed, but parents may well find that these brief encounters hardly justified the expense

Table 8 Proposed audit levels in general paediatric clinics

\begin{tabular}{ll}
\hline Maximum total clinic time (min) & 210 (consultation: 180, organisation: 30$)$ \\
Allocated time/patient (min) & No block booking. New: 30, review: 10-15 \\
Maximum No of patients/clinic & Single handed: $13,+1$ assistant: $22,+2$ assistants $: 30$ \\
Maximum No of patients/assistant & 10 \\
New/follow up & At least $25 \%$ \\
Appointment delay & Urgent: 1 week, non-urgent: 3 weeks \\
Attendance rate & More than $70 \%$ \\
Follow up continuity & Review patients see consultant $>50 \%$ visits \\
Outpatient waiting time & Mean: $<30$ minutes; no patients wait $>1$ hour \\
Audit & Quarterly \\
Consumer survey & Annual (+ outpatient waiting time check) \\
\hline
\end{tabular}

and inconvenience of a journey to hospital. Telephone calls and letters will usually be a quicker way of conveying the good news of a normal result, which is anxiously awaited. Smithells describes his practice of using 'telephone appointments' to supplement the regular review of, for example, epileptics. ${ }^{1}$ Sending parents a copy of the letter to the general practitioner after a hospital visit will help them to accept diagnosis and management and will make some return visits unnecessary: the results of investigations can sometimes be added in postscript.

Non-attendance is wasteful but widespread: many clinics are run on the risky and inefficient assumption that a quarter of the patients will default. It may be worth asking parents (as well as oneself) whether a further visit is necessary. When review appointments are at long intervals a reminder letter beforehand will help: defaulted appointments were reduced thereby from $20 \%$ to $8 \%$ in one hospital. ${ }^{8}$ Morning clinics are preferred by many parents, and attendance is likely to improve given punctual appointments and adequate consultation time. Punctuality will also be helped by individual appointment times: block booking ( $34 \%$ in this survey) in paediatric clinics does not work well. Habitual non-attenders may need a home visit from a health visitor to find whether further appointments would be kept: instead the paediatrician could make a domiciliary visit.

Consultants must take responsibility for the appointment system, designing a schedule of timing appropriate for their needs. They should read referral letters themselves and allocate appointments by the degree of urgency. Some patients may be seen more appropriately as ward attenders and some may not need to be seen at all but only a letter written to the general practitioner and parents-for example, some inquiries about pertussis immunisation. Spaces in the system should be reserved for urgent appointments, preferably at the start or end of the clinic. Some consultants find that separating clinics for new and review patients improves timekeeping and attendance. Punctuality on the consultant's part is of paramount importance ( $16 \%$ clinics started at least 30 minutes late).

This survey revealed that the chaotic conditions of some clinics made outpatient work (always challenging) very unpleasant. My own solution has been to increase my consultation time and reduce the number of patients reviewed. It is important to provide for dictation time, a tea break, and a preliminary opportunity to read casenotes. Appropriate planning is needed for holidays, absence of junior staff, and the presence of medical students. Only very urgent telephone calls should be referred to the clinic.

AUDIT

Finally, regular audit of outpatient activity will help. Some schemes have been published, but these mainly consists of casenote review. ${ }^{9-11} \mathrm{An}$ annual consumer survey should uncover other unmet needs, but the providers of the service must be prepared to respond positively. Table 8 lists some proposals for outpatient audit, to apply to general medical paediatric practice. 
Size of clinics is crucial: 21 of 40 general medical clinics studied were within the proposed limits, which derive from this survey but have been supported by useful data from another source (K L Dodd, Derbyshire Children's Hospital, 1990, personal communication). I hope that these suggestions will provide the starting point for change: not all paediatricians will find these standards will suit their particular style, nor the needs of their patients. Our service would be considerably improved by these suggestions, and we would be able to join Smithells in praise of outpatients clinics: 'an unrivalled opportunity to practise and demonstrate the holistic approach to paediatrics'.

I thank the West Midland paediatricians who helped with yet another tedious survey and Dr M E MacGregor for his improvements to the manuscript.
1 Smithells RW. In praise of outpatients: partnership in paediatrics. In: Apley J, Ounsted C, eds. One child. Clinics in developmental medicine, 80. London: Spastics Interin developmental medicine, 80. London: Spastics International

2 Andrews R, Morgan JD, Addy DP, McNeish AS. Understanding non-attendance in outpatient paediatric clinics. Arch Dis Child 1990;65:192-5.

3 Dawson KP, Ford RPK. Who comes to a paediatric medical outpatient clinic? New Zealand Medical fournal 1988;101: 111-2.

4 Anonymous. To come again-3 months [Editorial]. Lance 1976;i:1168-9.

5 Marsh GN. Are follow up consultations at medical outpatients futile? BMF 1982;284:1176-7.

6 Kiff RS, Sykes PA. Who undertakes consultations in the outpatient department? BMF 1988;296:1511-2.

7 Valman HB. Services for children: outpatient clinics and day care. $B M \mathcal{F}$ 1982;284:963-6.

8 Riseborough P. Outpatients: the outsiders? Nursing Times 1989;85:61.

9 Primavesi R, MacFaul R. Paediatric medical audit. Arch Dis Child 1990;65:1170-3.

10 British Paediatric Association. Paediatric audit. Report of a BPA Working Group. London: BPA, 1990:1-16.

11 Samanta A, Haider Y, Roffe C. An audit of patients attending a general medical follow-up clinic. $\mathcal{f} R$ Coll Physicians Lond $1991 ; 25: 33-5$. 